Article

\title{
Policy Zoning for Efficient Land Utilization Based on Spatio-Temporal Integration between the Bicycle-Sharing Service and the Metro Transit
}

\author{
Qing Yu ${ }^{1,2}$, Weifeng $\mathrm{Li}^{1, *}$, Dongyuan Yang ${ }^{1}$ and Yingkun Xie ${ }^{1}$ (D) \\ 1 Key Laboratory of Road and Traffic Engineering of the Ministry of Education, Tongji University, \\ 4800 Cao'an Road, Shanghai 201804, China; 1810514@tongji.edu.cn (Q.Y.); yangdyk@tongji.edu.cn (D.Y.); \\ 1931295@tongji.edu.cn (Y.X.) \\ 2 Center for Spatial Information Science, The University of Tokyo, 5-1-5 Kashiwanoha, Kashiwa-shi, \\ Chiba 277-8568, Japan \\ * Correspondence: liweifeng@tongji.edu.cn
}

check for updates

Citation: Yu, Q.; Li, W.; Yang, D.; Xie, Y. Policy Zoning for Efficient Land Utilization Based on Spatio-Temporal Integration between the Bicycle-Sharing Service and the Metro Transit. Sustainability 2021, 13, 141. https://dx.doi.org/10.3390/ su13010141

Received: 30 November 2020 Accepted: 21 December 2020 Published: 25 December 2020

Publisher's Note: MDPI stays neutral with regard to jurisdictional claims in published maps and institutional affiliations.

Copyright: () 2020 by the authors. Licensee MDPI, Basel, Switzerland. This article is an open access article distributed under the terms and conditions of the Creative Commons Attribution (CC BY) license (https: / / creativecommons.org/ licenses/by/4.0/).

\begin{abstract}
Dockless bicycle-sharing is one of the novel transportation modes that emerged in recent years. As a component of the public transit system, it plays an important part in connecting the urban metro system but also generates some problems. With the low parking turnover rate, the oversupply of bicycles will generate parking demand and occupy a large amount of urban public land. To make the dockless bicycle-sharing service a more effective travel mode for connecting the metro system, it is necessary to implement policy zoning with different management strategies for efficient land utilization in the dockless bicycle-sharing system. In this paper, the bicycle-sharing trips data and the metro trips data are utilized to extract indexes to assess the connection performance and operation potential between the bicycle-sharing system and metro transit system. A methodology of coverage area division and policy zoning based on cycling attraction area areas is used. Applying the methodology proposed to a case study in Shanghai, the metro stations in Shanghai are classified into four clusters with different characteristics, including stations with effective land utilization, stations with the potential to promote BS service, stations with deficiencies in BS service, and stations with the potential to improve the land utilization efficiency. According to the different demand patterns and operation performance of the four clusters, corresponding policy suggestions are proposed.
\end{abstract}

Keywords: dockless bicycle-sharing system; policy zoning; efficient land utilization; cycling attraction area; principal component clustering

\section{Introduction}

Bicycle-sharing (BS) is the novel transportation mode emerging in recent years. It has been warmly accepted by the public in a significant number of cities around the world [1]. The number of cities operating a bicycle-sharing platform (BSP) has increased from 13 in 2004 to 855 as of 2014. The global BS fleet is estimated at 946,000 bicycles, of which 750,500 are in China [2]. As a supplementary of the public transport system, BS is an ideal public transport mode to overcome the barriers to seamless door-to-door journeys. In most metropolitan cities operating metro systems, many residences and businesses are likely to be situated farther than an easy walking distance to a metro station, which is known as the "last mile" problem [3]. In Shanghai, dockless BS service is mainly considered as an important supplement of public transportation system and is introduced to serve the public's short-distance travel demand, solves the "last mile" problem, and provides a green, low-carbon, and eco-friendly travel mode. It is also considered to play a positive role in alleviating urban traffic congestion [4]. The BS service also enables metro passengers to avail shared transportation for short urban trips between their residences or businesses and metro stations, which provides door-to-door journeys and improves the accessibility of the metro system. 
The BS system used to have docking stations. The density and the location selection of docking stations largely affect the system operation performance. The traditional dockdependent BS system does not take users exactly where they need to go, and docking is not always available everywhere they go. When adopted to solve the last mile problem between a traveler's origin/destination and a metro station, the traditional service mode is barely effective and even likely to generate another last-mile problem between the traveler's origin/destination and docking station $[3,5]$.

Not long before, the Internet-based dockless BS system appeared on the market. For example, Mobike, one of the most popular BS operators in China, provides bicycles equipped with smart locks and unlocked through a mobile phone application. Mobike abandons fixed BS dock stations and allows users to park their bikes at any side of the road as long as there is a government-drawn parking area [6].

The novel BS system offers opportunities to completely solve the "last mile" demand, but it also generates some new problems. The supply and demand relationship of the dockless shared bicycles is an awkward dilemma in many cities. For some metro stations serving residential districts, the dockless bicycles are likely to have low parking turnover rates in the daytime. The oversupply of bicycle fleets near the metro stations will generate parking demand and occupy a large amount of urban public land. From the data in Shanghai, we find that the BS system will averagely occupy $231 \mathrm{~m}^{2}$ urban public land for bicycle parking around each metro station, and the maximum one requires $1634 \mathrm{~m}^{2}$ (Tongji University station). Without proper management, the lack of parking space will lead to the block of sidewalks and even traffic jams [7]. On the contrary, the demand of bicycle fleets is likely to exceed supply around these metro stations in the evening peak hours. The stock of bicycle fleets around the metro stations cannot meet the "last mile" traveling demand of commuters from work.

System layout design plays an important part in the system's implementing performance [8,9]. To ensure efficient land utilization in a dockless BS system, the system layout of dockless BS service should be carefully designed and improved to enhance the parking turnover rate of bicycles. It is necessary to implement different management strategies according to the bicycle utilization around the metro stations as well as the passenger flows of the stations. Since dockless bicycles are moving dynamically in the city, management strategies should not only focus on several specific locations but also cover a certain range of areas [10]. Therefore, the definition of the coverage area and policy zoning based on sub-area division are highly essential and fundamental [11].

In this paper, a methodology of policy zoning for efficient land utilization in a dockless bicycle-sharing system is proposed. The data respectively collected from the BS system and metro system are utilized to assess the operation performance of the two systems and evaluate the spatio-temporal integration between them. The rest of this paper is organized as follows-Section 2 presents the related works of the BS system layout design and optimization; Section 3 presents the data fusion of the two systems and the methodology of the index calculation and policy zoning; Section 4 presents the case study in Shanghai; Section 5 summarizes the conclusions of this study and proposes some future directions.

\section{Related Works}

Recent studies of bicycle sharing systems have mainly focused on the following aspects.

Many researchers focus on introducing the concept, history, generations, and development of the BS system [12-14]. The concept of BS has been around since the 1960s [2], and Parkes et al. summarized the four "generations" of evolution of bicycle sharing systems [15]. In the policy context of increasing dependency on private travel modes, in recent years, bicycle sharing as an ecofriendly and healthy mode is embraced by city administrators that has witnessed an extraordinary growth [16].

Optimizing the system layout of the BS system is a hot topic in recent studies. The design of BS system layout includes the siting of bicycle stations, the management policy, 
and the dispatching and rationing strategy. The existing methods can be divided into two types: mathematical programming models and GIS-based methods [8]. The mathematical model approach usually develops mixed-integer linear programming (MILP) or mixedinteger nonlinear programming (MINLP) models to plan a new BS system [17]. The GIS-based approach makes use of GIS as a tool to measure potential demand and optimize bicycle facility in BS systems [18-21].

Demand prediction of bicycle sharing systems has also received much attention. The existing demand predicting research studies mostly focus on three levels [22]: the city level, cluster level, and station level. Researchers forecast the hourly or daily BS demand. More recently, deep learning models have been widely used to solve spatio-temporal transportation demand prediction and produce more precise predicting results [22-29]. Such methods include Ridge Regression, Adaboost Regression, Support Vector Regression, Random Forecast Tree and Gradient Boosting Regression Tree, Convolutional Neural Network (CNN), Graph CNN (GCNN), etc.

The social, environmental, and public health benefits of the BS system are also areas of interest to researchers [30,31]. A growing awareness of bicycle sharing as a daily mobility option can reduce auto use and enhance the city's sustainable competitiveness [32]. Cycling also has great benefits on public health outcomes include reducing morbidity levels associated with urban disease [33]. Under the background of global warming, designing a BS system with high acceptance by the public can also mitigate the outcome of climate change and reduce urban emission [11].

Under the concept of shared mobility, it is an important issue for urban sustainable transport planning to evaluate the possibility of new transport modes as sustainable solutions for urban transport. Marianna et al. present an approach to modeling cycling in cities using the PTV VISUM to predict the effects of bicycle traffic in urban conditions [34]. Maria et al. developed a mathematical model to support the multi-criteria decision-making process, which can offer city planners potential information to find out which is a piece of significant information in the development of the metropolitan transport system [35]. Recently, the emerging pervasive, geospatial data and the big data processing technology with high computing capability has triggered an opportunity for studying the new sharing-based travel mode at the individual level. Data-driven research aim to find the hidden patterns that are difficult to discover by the traditional methods and summarize the application value in real-world situations [36,37].

As a newly emerged sharing transportation mode, studies have shown the strong connections between BS and urban metro systems, which has proven to largely increase the attractiveness of the metro. However, assessing the connection performance or operation potential of the two systems is still a research gap. Nowadays, the emerge of Internet-based bicycle sharing systems generates large amounts of geospatial data, which can support us in studying the detailed usage pattern and parking demand of bicycles, which offer us opportunities to divide the coverage area and policy zoning for BS systems.

\section{Methodology}

\subsection{Framework}

The methodology framework of this study is shown in Figure 1. In this paper, we use the data of BS trips and the data of metro passenger flows to assess the spatio-temporal integration between the two systems. In brief, the methodology is as follows.

Identification of bicycling-sharing trips associated with metro stations. The origin (O) and destination (D) for each BS trip are identified from the data of BS trips. BS trips departing from or arriving at the places within a set distance to the metro stations are identified as the cycling trips associated with metro stations.

Analysis of the spatio-temporal integration between the two systems. Combining with the patterns of metro passenger flow, ten indexes are proposed to assess the spatiotemporal integration between the two systems in three aspects: the interchange demand 
between the two systems, the bicycle parking demand around metro stations, and the attraction areas of cycling access to metro stations.

Classification of metro stations and guidance on the zonal operation. Applying the principal component clustering method, metro stations are classified based on the spatiotemporal integration with the BS system. The guidance on the operating strategy and efficient land utilization is given in the attraction areas of cycling access to metro stations.

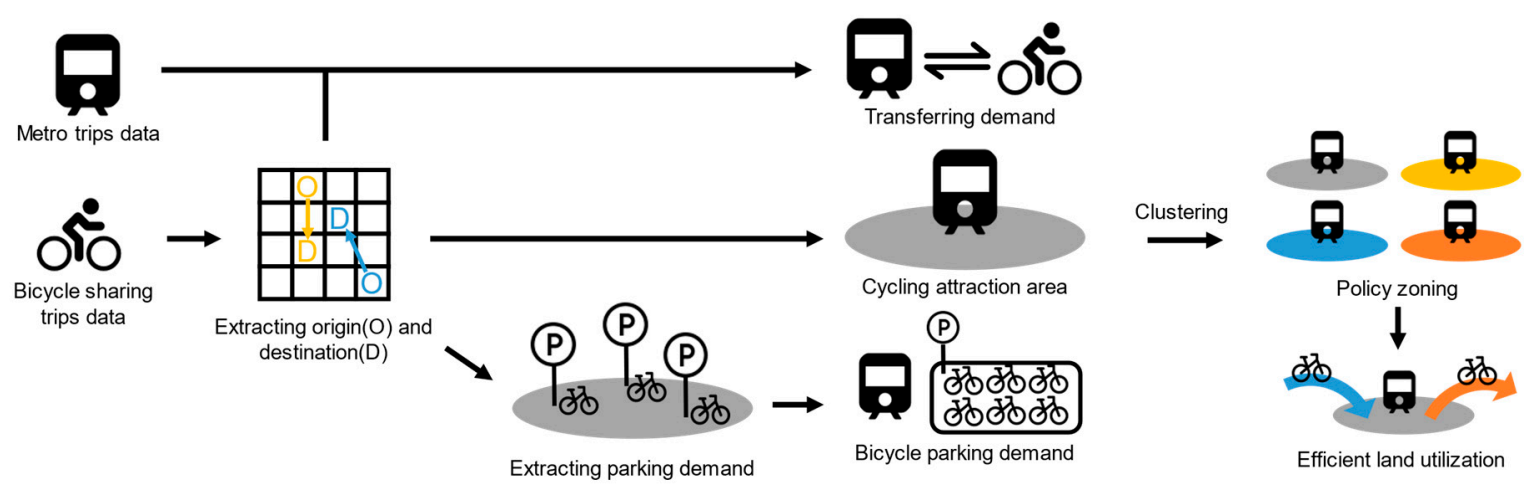

Figure 1. Framework of methodology.

\subsection{Identification of Cycling Trips Associated with Metro Stations}

Although BS trips bare no relation to metro trips based on the data collected from the two systems respectively, a basic assumption is proposed to establish the connection between the two systems: The BS trips whose origins or destinations are within a certain distance to metro stations are regarded as the trips associated with the metro system. Here, this distance is set to be $500 \mathrm{~m}$. In this paper, the non-metro ends of cycling trips associated with metro stations refer to the origins of cycling trips coming to metro stations or the destinations of cycling trips leaving from metro stations.

Given a time window $\Delta t$ in the BS trips data, there are $o_{i}$ cycling trips departing from the metro station $i$ and $d_{i}$ trips arriving at this station. Meanwhile, there are $o_{i}^{\prime}$ boarding passengers in the metro station $i$ and $d_{i}^{\prime}$ alighting passengers in this station. Then, the proportion of boarding passengers who take BS to the metro station $i$ can be calculated as Equation (1):

$$
D=\frac{d_{i}}{o_{i}^{\prime}} .
$$

Likewise, the proportion of alighting passengers who pick up BS to leave from the metro station $i$ can be calculated as Equation (2):

$$
A=\frac{o_{i}}{d_{i}^{\prime}} .
$$

The utilization rate of BS fleets at the metro station can be calculated by Equation (3):

$$
U_{r}=\frac{o_{i}+d_{i}}{N_{i}}
$$

where $N_{i}$ is the total number of distinct bicycles in $o_{i}$ and $d_{i}$. $U_{r}$ denotes the average utilized times for each bicycle around the metro station.

\subsection{Cycling Attraction Area Assessment}

The cycling attraction area of a metro station is the acceptable range of areas for travelers to choose cycling modes to depart from or arrive at the metro station and take metro transit to complete their travel purposes [38]. The study of cycling attraction area reflects the integration of the two systems in the spatial dimension. 
The existing methodologies of cycling attraction area assessment are conducted based on the ring buffer [39] and Voronoi Diagram [38]. These methods estimate the attraction area based on spatial analyzing tools without considering the demand in the real world. From the bicycle trips data, the cycling attraction area of metro stations can be obtained from the behavior of travelers and the spatio-temporal integration between the two systems.

The bicycle trips data show the connection between metro stations and other points in the space with bicycle trips. To analyze the cycling attraction area, the confidence region represented as an ellipse is introduced to describe the cycling attraction areas for metro stations, which provides indicators to describe the spatial dispersion of BS connection demand. For the method of constructing the confidence ellipse, please refer to the paper [40].

For each metro station, cycling trips associated with the station are identified as mentioned above. The spatial confidence ellipse is constructed based on the scatter plot of the non-metro ends of the identified trips. The center of the output confidence ellipse is supposed to be coordinated at the average center of the non-metro ends. The semi-major axis of ellipse with the length $a$ and the semi-minor axis with the length $b$ represent the direction of data distribution and the range of demand distribution, respectively. The size of the confidence ellipse represents the size of the attraction area and can be calculated by Equation (4):

$$
s=a b \pi \text {. }
$$

The oblateness of the confidence ellipse, also known as the first flattening, measures the difference between the semi-major and minor axis and describes the spatial directionality of the attraction area. The oblateness can be calculated by Equation (5):

$$
O_{b}=\frac{a-b}{a}
$$

The oblateness is zero for a circle. In the scenario of BS demand, if the oblateness is close to zero, it indicates that the non-metro ends of the associated cycling trips scatter evenly in different directions. The larger the oblateness, the larger the directionality of the cycling demand, indicating that a large proportion of bicycle users share similar traveling patterns in a similar direction. Figure 2 shows examples of attraction areas of two metro stations that are represented by the confidence ellipse.

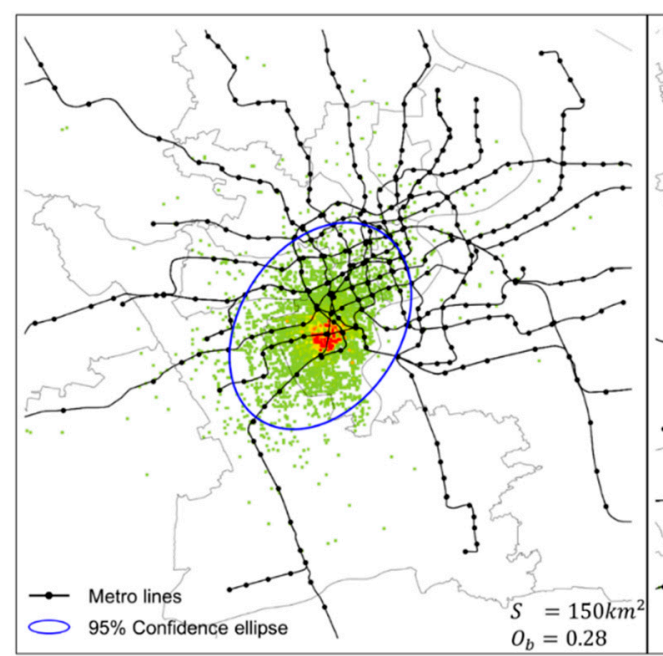

(a) Caobao Road Station

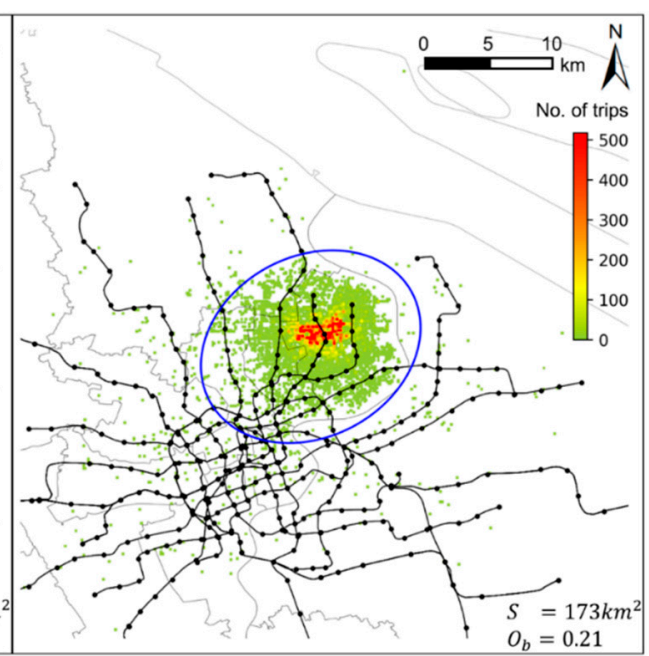

(b) Jiangwan Stadium Station

Figure 2. Example of cycling attraction areas represented by the confidence ellipse. 


\subsection{Evaluation of Bicycle Parking Land Demand}

BS demand in a city is unevenly distributed, which will inevitably generate parking demand in a certain range of areas, especially in regions with large traffic attraction such as metro stations, central business districts, etc. When considering the spatio-temporal integration of the metro system and BS system, the bicycle parking demand at metro stations is a significant factor. Large parking demand exceeding the supply parking lots will block the street, lead to the low utilization rate of bicycles, and seriously affect the acceptance of the public [7,11].

From the bicycle trips data, the bicycle parking demand can be extracted by using the following method. Given two consecutive trips of a bicycle Trip ${ }_{i}\left(\right.$ origin $_{i}$, destination $_{i}$, st $_{i}$, et $\left._{i}\right)$ and Trip ${ }_{i+1}$ origin $_{i+1}$, destination $\left._{i+1}, s t_{i+1}, e t_{i+1}\right)$, where origin $_{i}$ is the origin of the bicycle trip and destination ${ }_{i}$ is the destination, $s t_{i}$ is the time of departure and $e t_{i}$ is the time of arrival. The previous bicycle trip will generate a parking demand at destination ${ }_{i}$ with the duration from $e t_{i}$ to $s t_{i+1}$. Notice that this method only considers the parking demand generated naturally by the user's travel behavior. In the real-world situation, destination $n_{i}$ is not necessary at the same location as origin $_{i+1}$ with the dispatching interfere by operation company.

According to the code for transport planning on urban road published by the Ministry Of Housing and Urban-Rural Development (MOHURD) of China, it was suggested that the area of public parking lot should be around $1.5-1.8 \mathrm{~m}^{2}$ per bicycle fleet [41]. Here, we set the parking area for each bicycle to be $1.5 \mathrm{~m}^{2}$; then, the minimum parking area required to meet the parking demand at each metro station can be calculated.

\subsection{Principal Component Clustering Analysis}

In previous sections, we proposed indexes describing the spatio-temporal integration between the two transportation modes in three aspects including transferring demand, cycling attraction area, and bicycle parking demand. Table 1 shows the overall indicators and their detailed information. Classification is a classical method to analyze the features of samples, yet it is a powerful tool to discriminate the metro stations with different patterns. By calculating all the indicators for each metro station, a principal component clustering method can be applied to classify the metro stations.

The indicators are initially normalized as the input of the algorithm. In order to avoid the influence of the correlation between variables on the classification results, a principal component analysis (PCA) algorithm is applied to reduce the dimensionality [42]. Given the input of the dataset $X=\left\{x_{1}, x_{2}, \ldots, x_{n}\right\}$, the PCA algorithm firstly decentralized the features by minus the mean value of each feature. After solving the eigenvalues for the covariance matrix $\frac{1}{n} \boldsymbol{X}^{\top} \boldsymbol{X}$, the corresponding eigenvectors of the largest $m$ eigenvalues are used to form the eigenvector matrix $\boldsymbol{P}_{(m)}$. The principal components decomposition of $\boldsymbol{X}$ with $m$ dimensions can be given as shown in Equation (6):

$$
\boldsymbol{T}_{(m)}=\boldsymbol{X} \boldsymbol{P}_{(m)} .
$$

By the dimension reduction using PCA, the explained variance ratio of each component can be given as shown in Equation (7):

$$
e_{i}=\frac{\lambda_{i}}{\sum_{i} \lambda_{i}}
$$

where $\lambda_{i}$ is the eigenvalues. Summing up $e_{i}$, the accumulative explained variance ratio is a measure of the proportion of information retained after reducing into $m$ dimensions, which can be given as Equation (8):

$$
A_{m}=\sum_{i=1}^{m} e_{i} .
$$

After condensing the information covered by multiple indicators into a few comprehensive components, the $k$-means clustering method is then applied to classify the 
samples [43]. The objective is to find a $k$ clusters segmentation $s$ for the samples and minimize the cluster sum of squares as shown in Equation (9):

$$
\underset{s}{\operatorname{argmin}} \sum_{j=1}^{k} \sum_{x_{i} \in S_{j}}\left\|x_{i}-\boldsymbol{\mu}_{j}\right\|^{2}
$$

where $x_{i}$ denotes the variables of the sample $i$ and $\mu_{j}$ is the mean value of all samples in cluster $S_{j}$.

Table 1. The indexes measuring connection performance between the bicycle-sharing (BS) system with metro transit.

\begin{tabular}{|c|c|c|}
\hline Aspect & Name of Indicators & Detail \\
\hline \multirow{5}{*}{$\begin{array}{l}\text { Spatio-temporal } \\
\text { integration }\end{array}$} & $\begin{array}{c}D_{m}- \\
\text { Departure_morning }\end{array}$ & $\begin{array}{c}\text { The proportion of boarding passengers who take BS to the metro station in } \\
\text { morning peak hours on weekdays }\end{array}$ \\
\hline & $A_{m}$-Arrival_morning & $\begin{array}{l}\text { The proportion of alighting passengers who pick up BS to leave from the } \\
\text { metro station in morning peak hours on weekdays }\end{array}$ \\
\hline & $\begin{array}{l}D_{e}- \\
\text { Departure_evening }\end{array}$ & $\begin{array}{c}\text { The proportion of boarding passengers who take BS to the metro station in } \\
\text { evening peak hours on weekdays }\end{array}$ \\
\hline & $A_{e}$-Arrival_evening & $\begin{array}{c}\text { The proportion of alighting passengers who pick up BS to leave from the } \\
\text { metro station in evening peak hours on weekdays }\end{array}$ \\
\hline & $\begin{array}{l}U_{r} \text { 一Utilization_rate } \\
T_{S} \text {-Total_trips }\end{array}$ & $\begin{array}{l}\text { The utilization rate of bicycles parking at the metro station (times per day) } \\
\text { The total number of BS trips associated with the metro station (per day) }\end{array}$ \\
\hline \multirow[t]{2}{*}{ Cycling attraction area } & S-Size & $\begin{array}{l}\text { The size of the } 95 \% \text { weighted confidence ellipse of the cycling attraction area } \\
\qquad\left(\mathrm{km}^{2}\right)\end{array}$ \\
\hline & $\mathrm{O}_{b}$-Oblateness & $\begin{array}{l}\text { The oblateness of the } 95 \% \text { weighted confidence ellipse of the cycling attraction } \\
\text { area }\end{array}$ \\
\hline \multirow{3}{*}{$\begin{array}{c}\text { Bicycle parking land } \\
\text { use }\end{array}$} & $\begin{array}{l}T_{r}- \\
\text { Parking_turnover_rate }\end{array}$ & $\begin{array}{c}\text { The ratio of the total number of trips to the maximum capacity of bicycle } \\
\text { parking lots }\end{array}$ \\
\hline & $P_{c}-$ & The minimum area of bicycle parking lots in need, measured by the maximum \\
\hline & Parking_area_demanded & bicycle parking demand of the metro station in a day $\left(\mathrm{m}^{2}\right)$ \\
\hline
\end{tabular}

\section{Results and Discussion}

\subsection{Data and Study Subject}

In this study, the data of BS trips covers more than 33 million cycling trips in Shanghai from May 1st to May 31st in 2019, averagely covering 1.07 million trips per day. The information on each bicycle trips includes bike ID, coordinates of origin, time of departure, coordinates of destination, and time of arrival. The spatial distribution of trips in the dataset can cover most of the central urban district of Shanghai; see Figure 3a.

The data of metro trips covers all the metro trips in Shanghai from May 1st to May 12th in 2019, with 70 million trips in total and an average of 5.86 million trips per day. The data of metro trips provides the hourly passenger flows of each metro station, including origin station (O), destination station (D), time period, and number of passengers.

Eliminating the metro stations with less than 10 bicycle trips connected per day, the remaining 324 metro stations are the subject of this study case; see Figure $3 \mathrm{~b}$. 


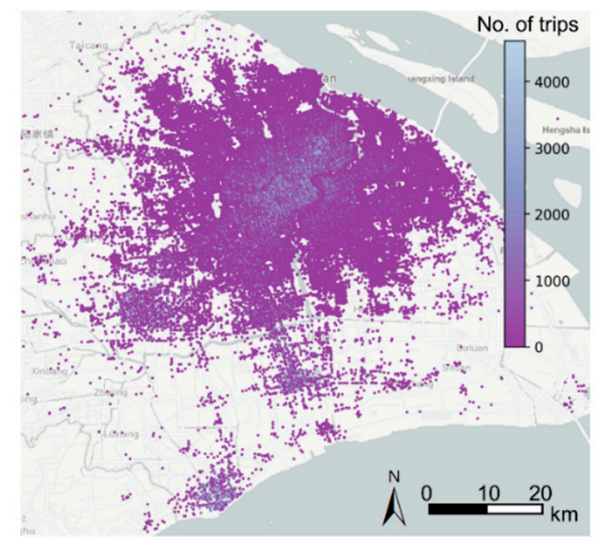

(a) Data distribution

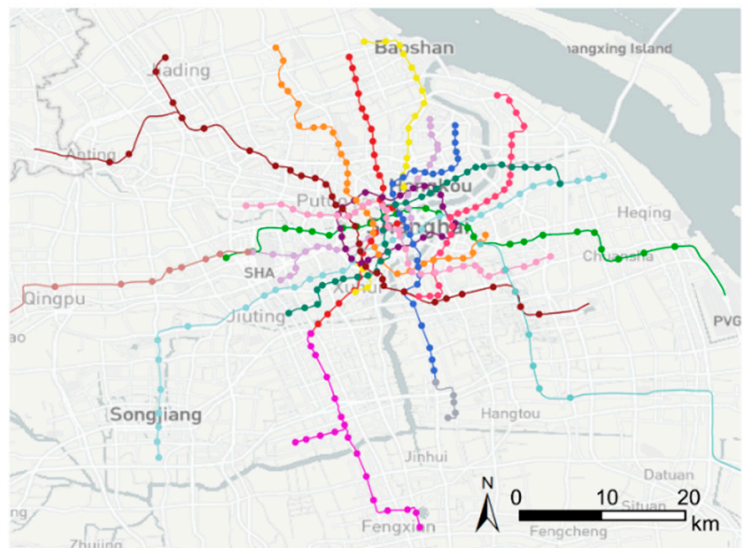

(b) Study subjects

Figure 3. Data distribution and study subjects.

\subsection{Spatio-Temporal Integration of the Two Systems}

By using the method proposed in the methodology section, bicycle trips associated with metro stations are identified. The total number of trips associated with metro stations is over 11 million, accounting for 34\% of the total BS trips. Figure 4a shows the temporal distribution of the number of identified trips by hour. It is evident that there is a morning peak around 7:00-9:00 and an evening peak around 17:00-19:00 on weekdays. On nonweekdays, morning peaks and evening peaks are not as obvious as those on weekdays. The number of identified cycling trips in the off-peak periods on both weekdays and non-weekdays is at the same level. Figure $4 \mathrm{~b}$ shows the spatial distribution of the metro stations and the number of identified cycling trips at the stations. In general, the cycling trips are more likely to be associated with the metro stations in the central urban areas of Shanghai, especially the metro stations near central urban districts, job centers, universities, large-scale transportation hubs, etc. Based on the spatio-temporal integration of the two systems, it is clear that BS has been widely accepted as the seamless access to metro stations and widely used in the peak commuting hours in the central urban districts.

\subsection{Result of Cycling Attraction Area}

After aggregating the data into $500 \mathrm{~m} \times 500 \mathrm{~m}$ grids spatially and identifying the metro stations with the most cycling trips associated for each grid, the cycling attraction area for each metro station is plotted as shown in Figure 4c. The areas with the same color are mostly connected to the same metro station. The identified attraction area is the basic support for policy zoning of the BS system.

The cycling attraction areas in the city center are much smaller than those in the suburban areas. In the suburban areas, a great number of the cycling attraction areas are shaped as rectangles. The centroids of rectangular attraction areas are likely to be located near the metro stations, and the lengths of rectangular attraction mainly extend perpendicularly to metro lines. The smaller the cycling attraction area, the more concentrated the cycling demand will be. On the contrary, the oversize cycling attraction areas indicate the difficulties of BS management, the demand of long bike rides, and the insufficient public transportation for the last mile problem in the area. Compared with BS, the community shuttle bus is a better choice in the oversize cycling attraction areas. 


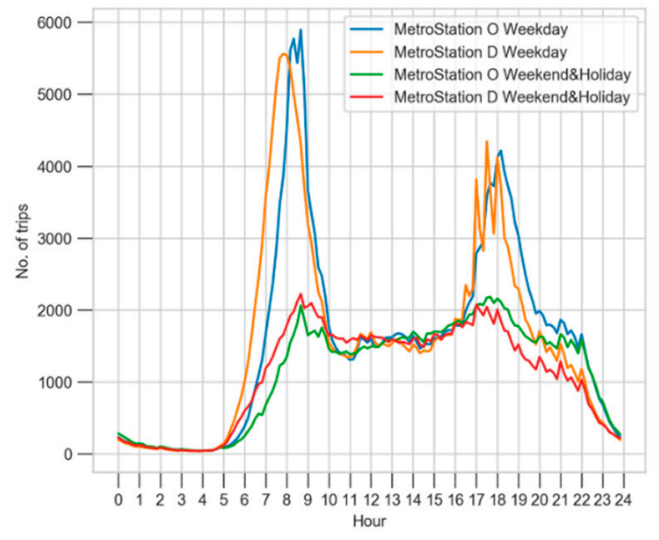

(a) Temporal distribution of trips

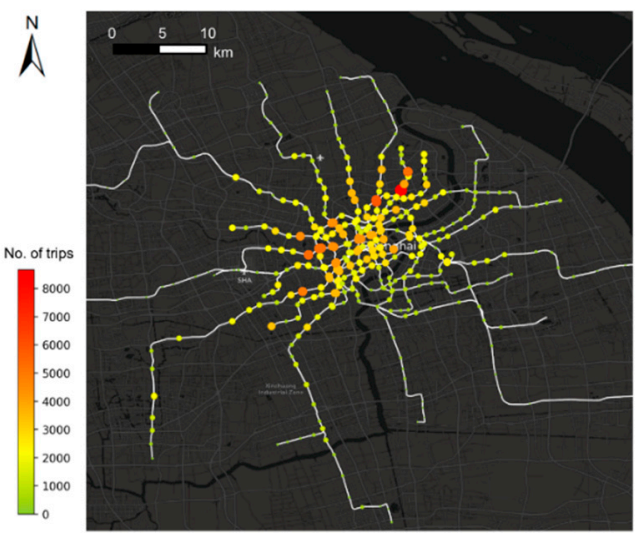

(b) Spatial distribution of trips

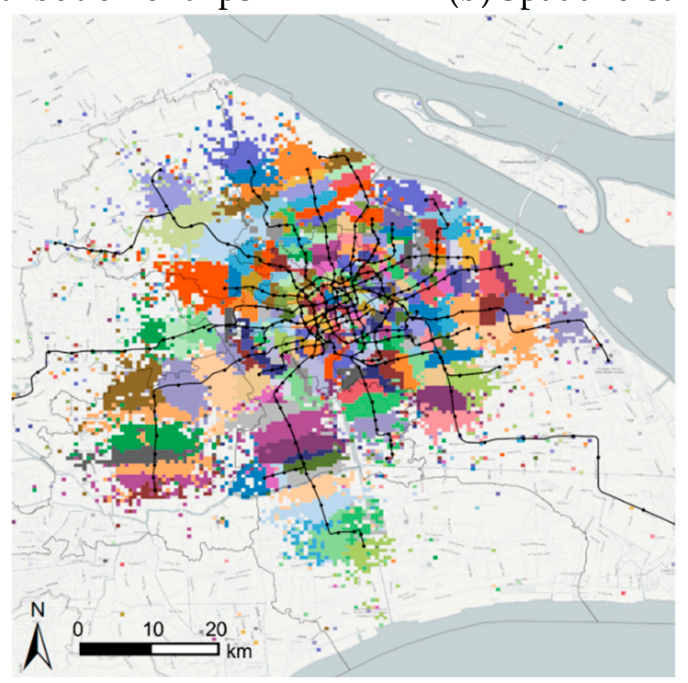

(c) Cycling attraction area

Figure 4. Transferring demand of metro stations.

\subsection{Result of Bicycle Parking Land Use}

Figure 5 shows the required parking capacity and the parking turnover rate calculated by the method proposed. The parking turnover rate here is an important index to reflect the potential of the BS system. With the same level of parking lots supply, the higher the parking turnover rate, the more efficiently the parking lots will be used, and the more the metro-associated cycling trips they can serve. The balance between BS demand and supply is discussed based on the two proposed indexes.

For the metro stations with high parking capacity required and low parking turnover rates, the BS supply exceeds the demand at the metro stations. For instance, Tongji University Station is the metro station with the most metro-associated cycling trips. According to the parking demand, at least $1634 \mathrm{~m}^{2}$ bicycle parking lots are required, but the parking turnover rate is just 4.15 . It indicates that although the BS system is well accepted by the public, the number of sharing bicycles around the metro station may exceed the actual demand. The redundancy of BS fleets at the metro station leads to the lack of bicycle parking space and the blocking of pedestrian walking space. For those metro stations with an oversupply of BS fleets, it is important to control and reduce the total number of the bicycles in the cycling attraction areas.

For the metro stations with low parking capacity required and high parking turnover rates, it shows either the potential to scale or the insufficient BS supply around the metro stations. The high turnover rate indicates the high potential of BS use, and the low parking capacity indicates the small stock of bicycles at the metro stations. These stations are mostly distributed in the suburban areas with large cycling attraction areas, where it is hard to 
manage and retain the number of bicycles. However, metro stations with small cycling attraction areas should be a potential market to scale up.

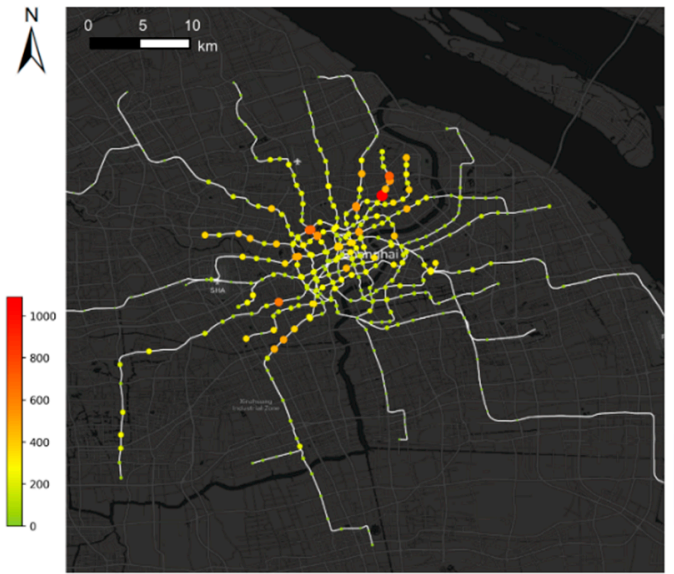

(a) Parking land demanded $\left(\mathrm{m}^{2}\right)$

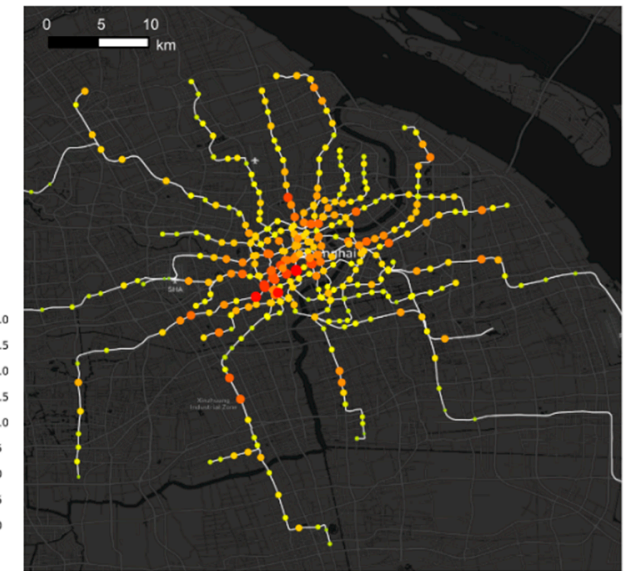

(b) Parking turnover rate

Figure 5. Evaluation of bicycle parking land use and turnover rate.

\subsection{Result of Policy Zoning for Bicycle-Sharing}

By using principal component clustering, the metro stations are classified into four clusters. Figure $6 \mathrm{a}$ shows the average normalized indexes of the four clusters, while Figure $6 \mathrm{~b}$ is the spatial distribution of metro stations in different clusters. As shown in Figure $6 c$, policy zoning is obtained according to the cycling attraction areas of metro stations. Metro stations in the four clusters show different patterns of spatio-temporal integration and operational potential. Political zones share the same patterns and categories with the metro stations in the zone.

\subsubsection{Stations with Effective Land Utilization}

Stations in this cluster are mainly distributed in the central urban areas, mostly in central business districts (CBDs), job centers, and industrial high-tech parks. The metro system can effectively integrate with the BS system, and the urban public land is utilized efficiently. Tidal flows are the most evident characteristics for the passenger flows of these stations. The metro passenger flow is mainly outbound in the morning peak and inbound in the evening peak, and it is unevenly distributed in both dimensions of direction and time on working days. These stations have high parking turnover rates and small parking areas are required, indicating the high frequency of bicycle handover, the small stock of fleets, and thus the high yield of operation. As for the cycling attraction areas of these stations, the patterns mentioned above represent the effective integration between the two systems in the area.

\subsubsection{Stations with Potential to Promote BS Service}

Stations in this cluster are mainly distributed in the peripheral area of the city center and mainly located in residential communities. There are no significant characteristics discovered through the indicators. For some metro stations, the moderate size of the cycling attraction areas shows that the BS system is applicable to solve the last mile problem for these stations. However, the total number of metro-associated cycling trips is relatively small, which has not yet formed a mature market with a high efficiency and high utilization rate. For these stations, the potential of the BS market remains to be explored. Increasing the bicycle supply in the cycling attraction areas can be a good attempt. For some other metro stations in this cluster, the cycling attraction areas present the characteristics of axial distribution. The community shuttle bus can be used as a replacement for long bike rides. 


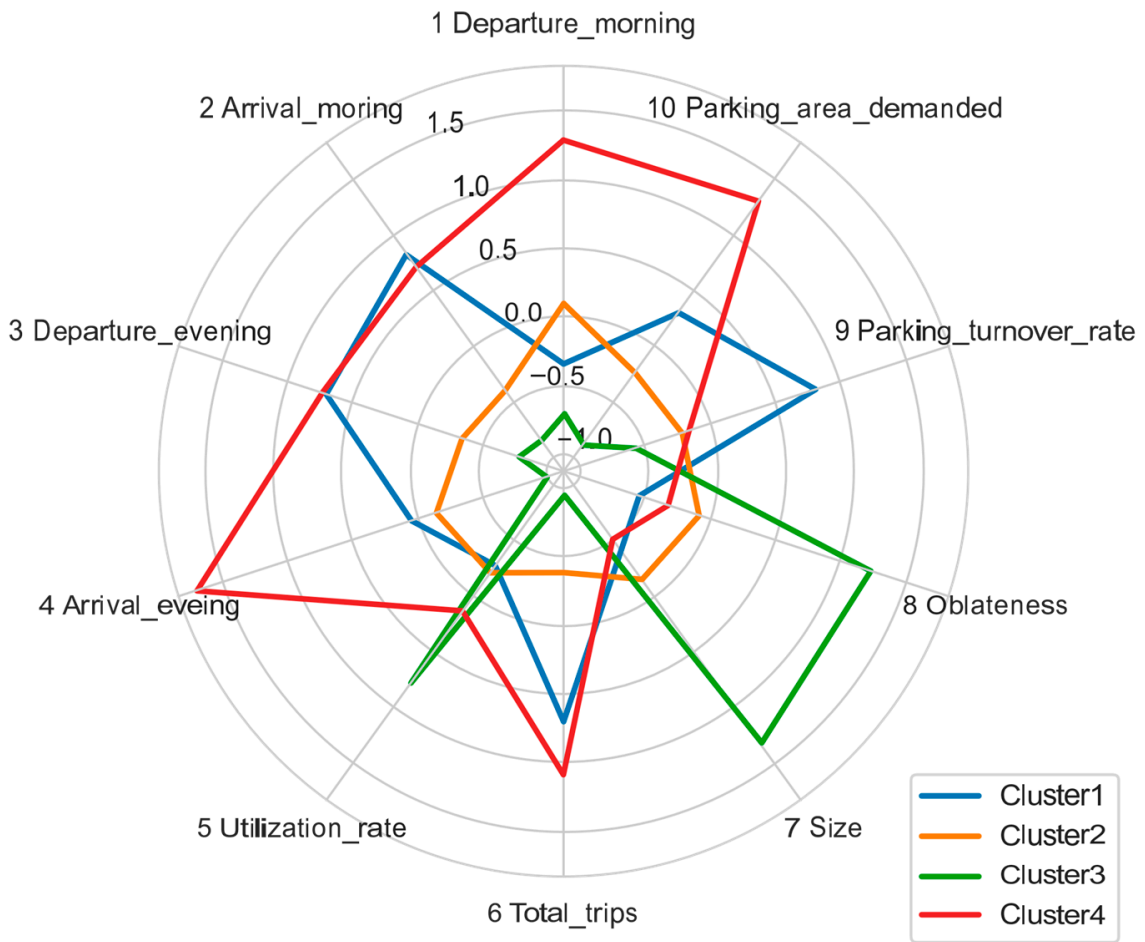

(a) Indexes of different clusters (normalized)

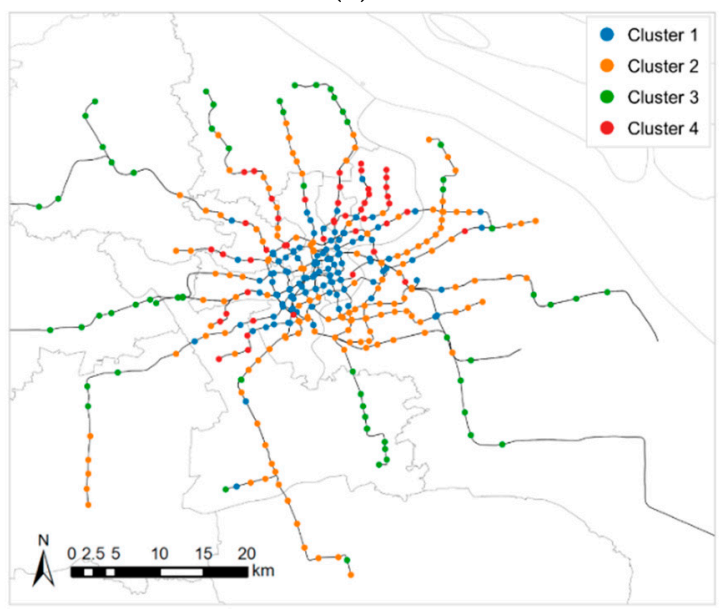

(b) Spatial distribution of clusters

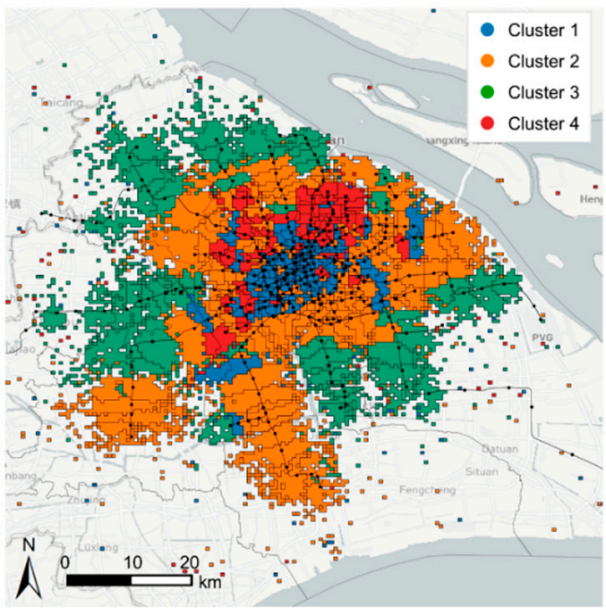

(c) Policy zoning

Figure 6. Result of principal component clustering.

\subsubsection{Stations with Deficiencies in BS Service}

Stations in this cluster are mainly distributed in the residential communities in the suburban areas. With the smallest volume of passenger flow and the largest size of the cycling attraction area of the four clusters, the BS mode is hard to manage or profit, which makes it unsuitable to solve the last mile problem by the BS service. The metro passenger flows are mainly inbound in the morning peak and outbound in the evening peak. However, the high utilization rate of the BS mode in these stations indicates the urgent need to solve the last mile problem in these stations. The cycling attraction areas of these stations have large oblateness and show an obvious tendency of axial distribution, indicating that the non-metro ends of the metro-associated cycling trips can be easily connected by a small number of bus lines. Therefore, the microcirculation bus transit or customized bus mode can be a good solution for the last mile problem in such stations. 


\subsubsection{Stations with Potential to Improve the Land Utilization Efficiency}

Stations in this cluster are mainly distributed in CBDs and important transportation hubs with mixed land use. The passenger flows of this type of station are the largest. Not only in the morning and evening peak but also passenger flows in the off-peak hours also remain at a high level. The small size of the cycling attraction areas indicates that the non-metro ends distribute evenly around the small area around the station. However, the BS system requires large areas around the stations for parking. The number of bicycle stock at the metro station is usually at a high level in most periods of the day with low parking turnover. This type of station is suitable to use shared bicycles to solve the last mile problem. More efforts should be put into the management of bicycle fleets and the promotion of bicycle parking area utilization efficiency at the metro stations.

\section{Conclusions and Future Directions}

In recent years, the dockless BS service has emerged and is warmly applauded by the public. As an environmentally friendly short-distance sharing travel mode, BS is widely accepted as a good solution for the "last mile" problem with a considerable part of BS trips connected to the metro stations. However, for some metro stations, using BS as a connection mode will generate problems related to the inefficiency of sharing bicycles with a low utilization rate and occupying large parking areas with a low turnover rate. For metro stations in different regions with different land use, they have different demand patterns and problems. Therefore, it is necessary to divide the policy zones and apply different management policy and optimization strategies, and to effectively promote the overall optimization of metro transit connectivity in the city.

In this paper, the data of BS trips and the data of metro trips are utilized. A methodology is proposed to evaluate the spatio-temporal integration between the two systems and the operation potential of BS system. Ten indexes are proposed from the aspects of spatio-temporal integration, cycling attraction area, and bicycle parking demand. Principal component clustering is applied to cluster the metro stations and generate policy zoning. Applying the methodology proposed to a case study in Shanghai, the metro stations in Shanghai are classified into four clusters with different characteristics, including stations with effective land utilization, stations with the potential to promote BS service, stations with deficiencies in BS service, and stations with the potential to improve the land utilization efficiency. According to the different demand patterns and operation performance of the four clusters, corresponding policy suggestions are proposed. Our research provides the management idea of policy zoning and a framework to analyze the connection between the dockless bicycle-sharing system with other modes of transportation. We believe that not only the methodology proposed but also the idea of problem-solving and the management framework are applicable to other cities with different conditions.

In future studies, further analysis will have several directions. For example, the urban built environment and land use in the cycling attraction areas can be taken into consideration in future studies. For the metro stations proved to be unsuitable and inefficient for BS connection in this study, it is suggested to choose the microcirculation bus transit or customized bus mode as the replacement to serve demand. For such travel modes, optimization and simulation models for bus line selection will be a significant research topic.

Author Contributions: The authors confirm contribution to the paper as follows: Study conception and design: Q.Y., D.Y. and W.L.; Data collection: D.Y. and W.L.; Analysis and interpretation of results: Q.Y. and W.L.; Draft manuscript preparation: Q.Y. and Y.X. All authors have read and agreed to the published version of the manuscript.

Funding: This work was supported by the National Key R\&D Program of China (No. 2018YFB1601100). Institutional Review Board Statement: Not applicable.

Informed Consent Statement: Not applicable. 
Data Availability Statement: The data presented in this study are available on request from the corresponding author. The data are not publicly available due to privacy issue.

Conflicts of Interest: The authors declare no conflict of interest.

\section{References}

1. Yu, D.-S.; Shang, L.-C. Opportunities and Challenges Faced by Share Economy: Taking Sharing Bicycle as an Example. DEStech Transactions on Environment, Energy and Earth Sciences Icmed (2017). Available online: http://dpi-proceedings.com/index $\mathrm{php} / \mathrm{dtem} /$ article/view/19328 (accessed on 21 December 2020). [CrossRef]

2. Fishman, E. Bikeshare: A review of recent literature. Transp. Rev. 2016, 36, 92-113. [CrossRef]

3. Liu, L.; Sun, L.; Chen, Y.; Ma, X. Optimizing fleet size and scheduling of feeder transit services considering the influence of bike-sharing systems. J. Clean. Prod. 2019, 236, 117550. [CrossRef]

4. Shanghai Municipal Government Office. Guidance on Encouraging and Regularizing the Development of Internet-Based Bicycle Sharing in Shanghai (in Chinese). Available online: http://www.shanghai.gov.cn/nw42621/20200823/0001-42621_1268301.html (accessed on 21 December 2020).

5. Shaheen, S.; Chan, N. Mobility and the sharing economy: Potential to facilitate the first-and last-mile public transit connections. Built Environ. 2016, 42, 573-588. [CrossRef]

6. Lan, J.; Ma, Y.; Zhu, D.; Mangalagiu, D.; Thornton, T. Enabling value co-creation in the sharing economy: The case of mobike. Sustainability 2017, 9, 1504. [CrossRef]

7. Ma, Y.; Lan, J.; Thornton, T.; Mangalagiu, D.; Zhu, D. Challenges of collaborative governance in the sharing economy: The case of free-floating bike sharing in Shanghai. J. Clean. Prod. 2018, 197, 356-365. [CrossRef]

8. Zhang, H.; Song, X.; Long, Y.; Xia, T.; Fang, K.; Zheng, J.; Huang, D.; Shibasaki, R.; Liang, Y. Mobile phone GPS data in urban bicycle-sharing: Layout optimization and emissions reduction analysis. Appl. Energy 2019, 242, 138-147. [CrossRef]

9. Zhang, L.; Zhang, J.; Duan, Z.-Y.; Bryde, D. Sustainable bike-sharing systems: Characteristics and commonalities across cases in urban China. J. Clean. Prod. 2015, 97, 124-133. [CrossRef]

10. García-Palomares, J.C.; Gutiérrez, J.; Latorre, M. Optimizing the location of stations in bike-sharing programs: A GIS approach. Appl. Geogr. 2012, 35, 235-246. [CrossRef]

11. Yu, Q.; Zhang, H.; Li, W.; Sui, Y.; Song, X.; Yang, D.; Shibasaki, R.; Jiang, W. Mobile phone data in urban bicycle-sharing: Market-oriented sub-area division and spatial analysis on emission reduction potentials. J. Clean. Prod. 2020, $254,119974$. [CrossRef]

12. Fishman, E.; Washington, S.; Haworth, N.; Mazzei, A. Barriers to bikesharing: An analysis from Melbourne and Brisbane. J. Transp. Geogr. 2014, 41, 325-337. [CrossRef]

13. Davis, L.S. Rolling along the last mile: Bike-sharing programs blossom nationwide. Planning 2014, 80, 10-16.

14. DeMaio, P. Bike-sharing: History, impacts, models of provision, and future. J. Public Transp. 2009, 12, 3. [CrossRef]

15. Parkes, S.D.; Marsden, G.; Shaheen, S.A.; Cohen, A.P. Understanding the diffusion of public bikesharing systems: Evidence from Europe and North America. J. Transp. Geogr. 2013, 31, 94-103. [CrossRef]

16. Handy, S.; Van Wee, B.; Kroesen, M. Promoting cycling for transport: Research needs and challenges. Transp. Rev. 2014, 34, 4-24. [CrossRef]

17. Chen, Q.; Sun, T. A model for the layout of bike stations in public bike-sharing systems. J. Adv. Transp. 2015, 49, 884-900. [CrossRef]

18. Rybarczyk, G.; Wu, C. Bicycle facility planning using GIS and multi-criteria decision analysis. Appl. Geogr. 2010, 30, 282-293. [CrossRef]

19. Landis, B.W. Bicycle system performance measures. ITE J. 1996, 66, 18-26.

20. Kabak, M.; Erbaş, M.; Çetinkaya, C.; Özceylan, E. A GIS-based MCDM approach for the evaluation of bike-share stations. J. Clean. Prod. 2018, 201, 49-60. [CrossRef]

21. Lopez Gonzalez, L. Optimal Location for Bike Sharing Stations in Downtown Kalamazoo; Western Michigan University: Kalamazoo, MI, USA, 2016.

22. Lin, L.; He, Z.; Peeta, S. Predicting station-level hourly demand in a large-scale bike-sharing network: A graph convolutional neural network approach. Transp. Res. Part C Emerg. Technol. 2018, 97, 258-276. [CrossRef]

23. Giot, R.; Cherrier, R. Predicting bikeshare system usage up to one day ahead. In Proceedings of the 2014 IEEE Symposium on Computational Intelligence in Vehicles and Transportation Systems (CIVTS), Orlando, FL, USA, 9-12 December 2014; pp. 22-29.

24. Zhou, X. Understanding spatiotemporal patterns of biking behavior by analyzing massive bike sharing data in Chicago. PLoS ONE 2015, 10, e0137922. [CrossRef]

25. Bao, J.; Xu, C.; Liu, P.; Wang, W. Exploring bikesharing travel patterns and trip purposes using smart card data and online point of interests. Netw. Spat. Econ. 2017, 17, 1231-1253. [CrossRef]

26. Li, Y.; Zheng, Y.; Zhang, H.; Chen, L. Traffic prediction in a bike-sharing system. In Proceedings of the 23rd SIGSPATIAL International Conference on Advances in Geographic Information Systems, Bellevue, WA, USA, 3-6 November 2015 ; p. 33.

27. Chen, L.; Zhang, D.; Wang, L.; Yang, D.; Ma, X.; Li, S.; Wu, Z.; Pan, G.; Nguyen, T.-M.-T.; Jakubowicz, J. Dynamic cluster-based over-demand prediction in bike sharing systems. In Proceedings of the 2016 ACM International Joint Conference on Pervasive and Ubiquitous Computing, Heidelberg, Germany, 12-16 September 2016; pp. 841-852. 
28. Rixey, R.A. Station-level forecasting of bikesharing ridership: Station network effects in three US systems. Transp. Res. Rec. 2013, 2387, 46-55. [CrossRef]

29. Faghih-Imani, A.; Eluru, N.; El-Geneidy, A.M.; Rabbat, M.; Haq, U. How land-use and urban form impact bicycle flows: Evidence from the bicycle-sharing system (BIXI) in Montreal. J. Transp. Geogr. 2014, 41, 306-314. [CrossRef]

30. El-Assi, W.; Mahmoud, M.S.; Habib, K.N. Effects of built environment and weather on bike sharing demand: A station level analysis of commercial bike sharing in Toronto. Transportation 2017, 44, 589-613. [CrossRef]

31. Li, P.; Zhao, P.; Brand, C. Future energy use and $\mathrm{CO}_{2}$ emissions of urban passenger transport in China: A travel behavior and urban form based approach. Appl. Energy 2018, 211, 820-842. [CrossRef]

32. Shaheen, S.A.; Guzman, S.; Zhang, H. Bikesharing in Europe, the Americas, and Asia: Past, present, and future. Transp. Res. Rec. 2010, 2143, 159-167. [CrossRef]

33. Qiu, L.-Y.; He, L.-Y. Bike sharing and the economy, the environment, and health-related externalities. Sustainability 2018, 10, 1145. [CrossRef]

34. Jacyna, M.; Wasiak, M.; Kłodawski, M.; Gołębiowski, P. Modelling of Bicycle Traffic in the Cities Using VISUM. Procedia Eng. 2017, 187, 435-441. [CrossRef]

35. Cieśla, M.; Sobota, A.; Jacyna, M. Multi-Criteria Decision Making Process in Metropolitan Transport Means Selection Based on the Sharing Mobility Idea. Sustainability 2020, 12, 7231. [CrossRef]

36. Yu, Q.; Li, W.; Zhang, H.; Yang, D. Mobile phone data in urban customized bus: A network-based hierarchical location selection method with an application to system layout design in the urban agglomeration. Sustainability 2020, 12, 6203. [CrossRef]

37. Yu, Q.; Zhang, H.; Li, W.; Song, X.; Yang, D.; Shibasaki, R. Mobile phone GPS data in urban customized bus: Dynamic line design and emission reduction potentials analysis. J. Clean. Prod. 2020, 272, 122471. [CrossRef]

38. Hu, L.; Lu, H. Study on the Cycling Attraction Area of Metro Station Based on Sharing Bike Riding Data: An Empirical Study in Beijing. In Proceedings of the 19th COTA International Conference of Transportation, Nanjing, China, 6-8 July 2019; pp. 4194-4206.

39. Lifan, D.; Yonghong, X.; Dingxi, H. Bicycle-sharing Facility Planning Base On Riding Spatio-temporal Data. Planners 2017, 10, 13.

40. Beh, E.J. Elliptical confidence regions for simple correspondence analysis. J. Stat. Plan. Inference 2010, 140, 2582-2588. [CrossRef]

41. MOHURD. Code for Transport Planning on Urban Road; Ministry of Housing and Urban-Rural Development: Beijing, China, 1995.

42. Wold, S.; Esbensen, K.; Geladi, P. Principal component analysis. Chemom. Intell. Lab. Syst. 1987, 2, 37-52. [CrossRef]

43. Jain, A.K. Data clustering: 50 years beyond K-means. Pattern Recognit. Lett. 2010, 31, 651-666. [CrossRef] 